\title{
Heat shock protein 70 polymorphisms in Chinese patients with Graves' disease
}

\author{
Y.P. Wang ${ }^{1 *}$, Z. Tang ${ }^{1 *}$, B.K. Peng ${ }^{1}$, Q. Zhen ${ }^{1}$, S.L. Zhou ${ }^{1}$ and X.F. Jin ${ }^{2}$ \\ ${ }^{1}$ Department of Endocrinology, Yan'an Affiliated Hospital of Kunming Medical \\ University, Kunming, China \\ ${ }^{2}$ Department of Geriatric, Yan'an Affiliated Hospital of Kunming Medical University, \\ Kunming, China \\ *These authors contributed equally to this study. \\ Corresponding author: X.F. Jin \\ E-mail: jinxf177@126.com \\ Genet. Mol. Res. 14 (4): 18376-18383 (2015) \\ Received August 14, 2015 \\ Accepted October 29, 2015 \\ Published December 23, 2015 \\ DOI http://dx.doi.org/10.4238/2015.December.23.25
}

\begin{abstract}
Graves' disease (GD) is a common autoimmune disease mainly affecting the thyroid. However, the correlation between the development of GD and HSP70 alleles has not been reported in the Chinese population. Therefore, the aim of this study was to investigate the association between HSP70 polymorphisms and GD in the Chinese population. A total of 153 patients with GD treated at the Yan'an Affiliated Hospital of Kunming Medical University between October 2010 and August 2013 were enrolled in this study; one hundred and twenty healthy volunteers were included in the control group. HSP70 polymorphisms at positions HSP70-1 +190, HSP70-2 +1267, and HSP70-hom +2437 were genotyped by polymerase chain reaction-restriction fragment length polymorphism. The distribution of the HSP70-2 +1267 GG genotype allele frequencies among GD and control subjects differed significantly $\left(X^{2}=\right.$ 20.40, $\left.\mathrm{P}<0.001 ; \mathrm{X}^{2}=18.18, \mathrm{P}<0.001\right)$. The $\mathrm{G}$ allele of HSP70-2 +1267 (Odds ratio $=0.455,95 \%$ confidence interval: $0.315-0.655$ ) conferred a higher risk of developing GD than the A allele. We observed no significant differences in the allelic frequencies of HSP70-1 +190 and HSP70-hom
\end{abstract}


+2437. Therefore, the HSP70-2 +1267 GG genotype and the G allele may increase the risk of GD in Chinese subjects. The results of this study may be useful in identifying patients with increased risk of GD, and offer useful reference data for targeted gene therapy of $G D$ in the future.

Key words: Graves' disease; Heat shock protein 70; Polymorphisms; Chinese population

\section{INTRODUCTION}

Graves' disease (GD), one of the most common autoimmune diseases, mainly affects the thyroid (Zheng et al., 2015); moreover, it affects other systems, such as the cardiovascular, central nervous, and reproductive systems, in addition to the eyes and bones (Streetman and Khanderia, 2003). GD patients develop immune function disorders that compromise immune tolerance and alter recognition and regulatory functions. Such GD-induced immune function disorders also cause functional defects in antigen-specific or non-specific suppressor $T$ lymphocytes; this prevents the body from controlling its immune response against its own tissues, and weakens helper $T$ lymphocyte inhibition by suppressor T cells. With the assistance of specific helper T lymphocytes, B lymphocytes produce autoimmune antibodies, such as TRAb, TPOAb, and TGAb.

The incidence of GD is mainly attributed to genetic factors; however, GD can be triggered by environmental factors, such as infection (Hammerstad et al., 2013, 2014) and psychological trauma (Vita et al., 2014). The exact cause of GD however remains unclear.

Heat shock proteins (HSPs) are chaperones for protein folding and stability. Heat shock response (HSR) occurs when cells are subjected to stress, such as ischemia, hypoxia, heat stimulation, and heavy metal poisoning, resulting in high-level expressions of heat shock proteins aimed at protecting the cells from stress hazards (Gabai et al., 1997). Depending on their molecular weight, HSPs can be divided into four subfamilies: HSP90-110, HSP70, HSP60, and HSP10-30 (Jin et al., 2004). The HSP70 subfamily contains three coding genes, HSP70-1, HSP70-2, and HSP70-hom (Westman et al., 1994). All HSP70 genes have continuous open reading frames that enable their rapid transcription and translation.

HSP70 gene polymorphisms are associated with several autoimmune diseases, including systemic lupus erythematosus (Fürnrohr et al., 2010), autoimmune arthritis (Wieten et al., 2010), and Crohn's disease (Chen et al., 2013). Although HSP70 alleles are reportedly associated with an increased risk of developing GD in Caucasians, the relationship between these alleles and the risk of GD in Chinese individuals remains unknown.

Based on this information, this study explored the association between HSP70 polymorphisms and GD in the Chinese population. In this study, a single nucleotide polymorphism (SNP) located at position HSP70-2+1267 was found to be correlated with GD risk in the Chinese population.

\section{MATERIAL AND METHODS}

\section{Subjects}

A total of 153 patients with GD treated at the Yan'an Affiliated Hospital of Kunming Medical University between October 2009 and October 2014 were recruited to this study. The age of the subjects was at a range of18 to 40 years. GD is defined as the presence of clinical and 
biochemical hyperthyroidism [including suppressed thyroid-stimulating hormone (TSH), elevated free triiodothyronine (FT3), and free thyroxine (FT4)], positive titers of TPOAb, TGAb, and TRAb, and B-ultrasonographic diffuse goiter at the first diagnosis (Lu and Zhong, 2008). Patients with a history of other diseases, such as hypertension, were excluded from this study. The control group was comprised of 120 healthy participants (as determined by regular health examinations at the hospital) from the same geographic area as the GD subjects. All control subjects exhibited normal TSH, FT3, and FT4 levels, and did not express TPOAb, TGAb, and TRAb.

$A$ validated questionnaire concerning the age, sex, and history of other diseases was completed by each participant.

This study was approved by the Ethical Committee of the Yan'an Affiliated Hospital of Kunming Medical University. An informed consent form was signed by all participants.

\section{Genotyping}

Blood samples were collected in the morning from all subjects after fasting for $12 \mathrm{~h}$. Peripheral blood (3-5 $\mathrm{mL}$ ) was collected using an EDTA-treated vacuum tube. Genomic DNA was isolated from the leukocytes using an AxyPrep Blood Genome DNA Isolation kit (Axygen, New York, NY, USA). HSP70-1 +190, HSP70-2 +1267, and HSP70-hom +2437 expressions were analyzed by polymerase chain reaction-restriction fragment length polymorphism (PCR-RFLP). The target sequences were amplified using a C1000 Touch Thermal Cycler (Bio-Rad, Hercules, CA, USA). The reaction system $(15 \mu \mathrm{L})$ contained approximately $0.2 \mathrm{ng}$ genomic DNA, $0.5 \cup$ Taq DNA polymerase, $0.3 \mu \mathrm{L}$ dNTPs ( $2.5 \mathrm{mM}$ each), and 5 pmol primer pairs. PCR amplification was conducted using the following cycling conditions: denaturation at $95^{\circ} \mathrm{C}$ for $5 \mathrm{~min}$; 20 cycles of denaturation at $95^{\circ} \mathrm{C}$ for $30 \mathrm{~s}$, annealing at $68.5^{\circ} \mathrm{C}$ for $45 \mathrm{~s}$, and extension at $72^{\circ} \mathrm{C}$ at $60 \mathrm{~s} ; 20$ cycles of denaturation at $95^{\circ} \mathrm{C}$ for $30 \mathrm{~s}$, annealing at $62^{\circ} \mathrm{C}$ for $30 \mathrm{~s}$, and extension at $72^{\circ} \mathrm{C}$ for $40 \mathrm{~s}$; and a final extension at $72^{\circ} \mathrm{C}$ for $6 \mathrm{~min}$. The PCR products were subjected to agarose gel electrophoresis on a $3 \%$ agarose gel.

\section{Statistical analysis}

The data was analyzed using SPSS v.21.0 (IBM, Armonk, NY, USA). The frequency of each genotype was calculated using a $X^{2}$ test. Odds ratios (OR) were calculated based on $95 \%$ confidence intervals $(95 \% \mathrm{Cl})$. Differences with $\mathrm{P}<0.05$ were considered to be significant.

\section{RESULTS}

\section{General data}

The percentage of male subjects in the GD group was $43.1 \%$, and the percentage of males in the control group was $43.3 \%$. No significant differences in age, gender, or alcohol drinking or smoking habits were observed between the two groups. The results are summarized in Table 1.

\section{Genotyping}

The electrophoresis bands of the analyzed alleles, HSP70-1 +190, HSP70-2 +1267, and HSP70-hom +2437 are presented in Figures 1-3. 
Table 1. Clinical characteristics of the subjects.

\begin{tabular}{lccc}
\hline Factors & Patients & Controls & P value \\
\hline Age (years) & $27.6 \pm 5.4$ & $26.7 \pm 5.2$ & 0.198 \\
Male/female & $66 / 87$ & $52 / 68$ & 0.974 \\
Alcohol drinking & 47 & 31 & 0.375 \\
Smoking & 42 & 35 & 0.755 \\
\hline
\end{tabular}

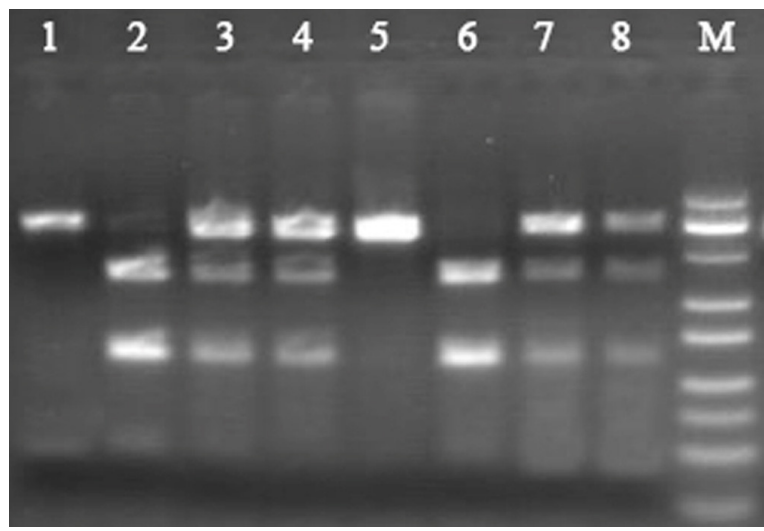

Figure 1. PCR digestion products: electrophoresis of HSP70-1 +190. Lane M contains the GM303 DNA marker; lanes 1 and 5 contained the genotype CC (359 bp); lanes 3, 4, 7, and 8 show the genotype GC (116, 243, and $359 \mathrm{bp}$, respectively); and lanes 2 and 6 contained the genotype GG (116 and $243 \mathrm{bp}$, respectively).

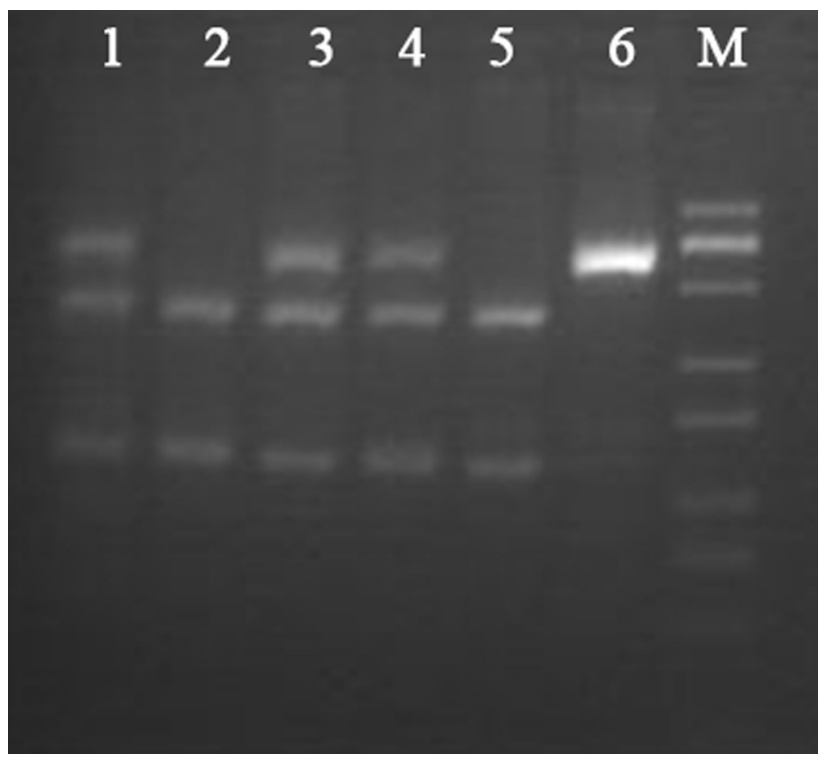

Figure 2. PCR digestion products: electrophoresis of HSP70-2 +1267. Lane M contains the GM303 DNA marker; lanes 2 and 5 contained the genotype GG (118 and 249 bp, respectively); lanes 1, 3, and 4 displayed the genotype GA (118, 249 , and $367 \mathrm{bp}$, respectively); and lane 6 showed the genotype AA (367 bp). 


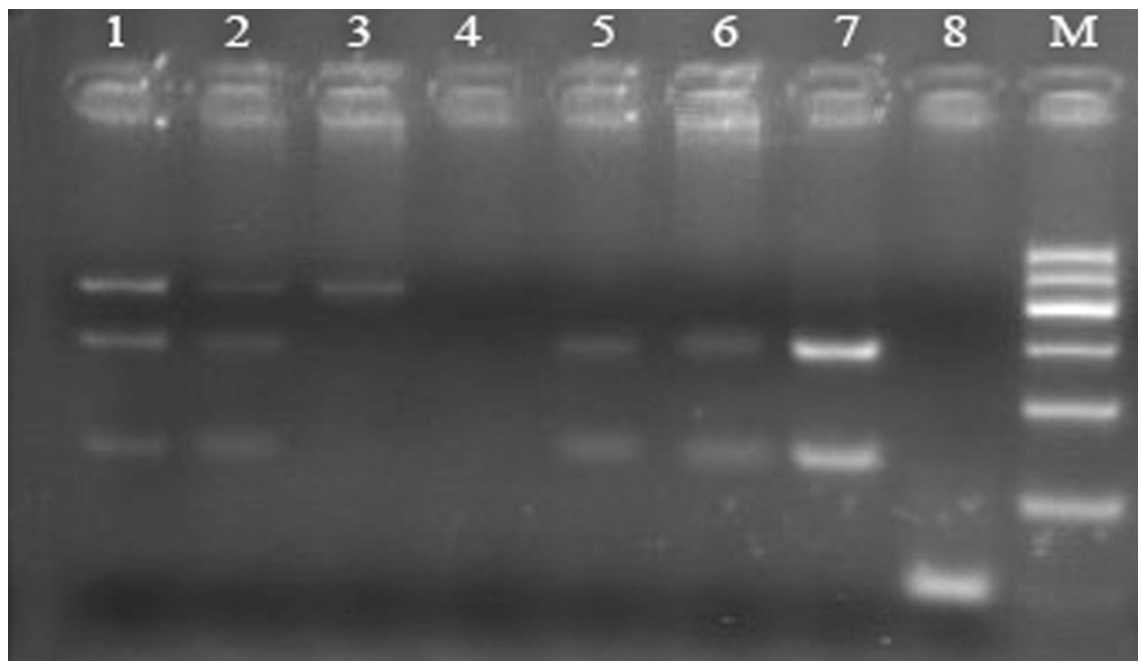

Figure 3. PCR digestion products: electrophoresis of HSP70-hom. Lane M contained the GM303 DNA marker; lanes 1 and 2 showed the genotype TC $(134,282$, and 416 bp); lane 3 expressed the genotype CC (416 bp); and lanes 5, 6, and 7 contained genotype TT (134 and 282 bp).

The results of our analyses revealed that the distributions of all genotyped polymorphisms in the HSP70 genes in the GD and control groups were consistent with the Hardy-Weinberg equilibrium (Tables 2-4). The frequencies of the HSP70-1 +190 G/C did not differ significantly between the GD and control groups (Table 5). Additionally, the frequency of the GG genotype and G allele at HSP70-2 +1267 in the GD group was significantly reduced compared to the control group (42.48 vs $31.67 \%, \mathrm{P}<0.01$; Table 6 ). However, the frequencies of the HSP70-hom +2437 $\mathrm{A} / \mathrm{C}$ polymorphisms did not differ significantly between the GD and control groups (Table 7).

Table 2. Distribution of HSP70-1 +190 alleles and Hardy-Weinberg equilibrium test data.

\begin{tabular}{|c|c|c|c|c|c|}
\hline & Number observed & Number expected & Gene frequency & $x^{2}$ & $P$ value \\
\hline Genotype in the GD group & & & & 2.970 & 0.085 \\
\hline $\mathrm{CC}$ & 3 & 7 & 0.020 & & \\
\hline GG & 93 & 96 & 0.608 & & \\
\hline $\mathrm{GC}$ & 57 & 50 & 0.372 & & \\
\hline Genotype in the control group & & & & 2.904 & 0.088 \\
\hline CC & 4.00 & 8 & 0.033 & & \\
\hline GG & 64.00 & 68 & 0.533 & & \\
\hline $\mathrm{GC}$ & 52.00 & 45 & 0.433 & & \\
\hline
\end{tabular}

Table 3. Distribution of HSP70-2 +1267 alleles and Hardy-Weinberg equilibrium test data.

\begin{tabular}{|c|c|c|c|c|c|}
\hline & Number observed & Number expected & Gene frequency & $x^{2}$ & $P$ value \\
\hline Genotype in the GD group & & & & 3.354 & 0.067 \\
\hline AA & 5 & 9 & 0.033 & & \\
\hline GG & 83 & 87 & 0.542 & & \\
\hline GA & 65 & 57 & 0.425 & & \\
\hline Genotype in the control group & & & & 1.132 & 0.287 \\
\hline AA & 18 & 21 & 0.150 & & \\
\hline GG & 38 & 41 & 0.317 & & \\
\hline GA & 64 & 58 & 0.533 & & \\
\hline
\end{tabular}


Table 4. Distribution of the HSP70-hom +2437 alleles and Hardy-Weinberg equilibrium test.

\begin{tabular}{|c|c|c|c|c|c|}
\hline & Number observed & Number expected & Gene frequency & $x^{2}$ & $P$ value \\
\hline Genotype in the GD group & & & & 0.213 & 0.645 \\
\hline $\mathrm{AA}$ & 7 & 8 & 0.046 & & \\
\hline GG & 90 & 91 & 0.588 & & \\
\hline GA & 56 & 54 & 0.366 & & \\
\hline Genotype in the control group & & & & 0.252 & 0.615 \\
\hline AA & 6 & 7 & 0.050 & & \\
\hline GG & 68 & 69 & 0.567 & & \\
\hline GA & 46 & 44 & 0.383 & & \\
\hline
\end{tabular}

Table 5. Statistical analysis of the frequencies of the HSP 70-1 +190 genotype and alleles in the GD and control groups.

\begin{tabular}{|c|c|c|c|c|}
\hline & GD group & Control group & $x^{2}$ & $P$ value \\
\hline Genotype & & & 1.766 & 0.414 \\
\hline CC & $3(1.96 \%)$ & $4(3.33 \%)$ & & \\
\hline GG & $93(60.78 \%)$ & $64(53.33 \%)$ & & \\
\hline $\mathrm{GC}$ & $57(37.25 \%)$ & $52(43.33 \%)$ & & \\
\hline Allele & & & 1.500 & 0.221 \\
\hline C & $63(20.59 \%)$ & $60(25.00 \%)$ & & \\
\hline G & $243(79.41 \%)$ & $180(75.00 \%)$ & & \\
\hline
\end{tabular}

Table 6. Statistical analysis of the frequencies of the HSP70-2 +1267 genotype and alleles in the GD and control groups.

\begin{tabular}{cccc}
\hline & GD group & Control group & $X^{2}$ \\
\hline Genotype & $5(3.27 \%)$ & $18(15.00 \%)$ & 20.40 \\
AA & $83(42.48 \%)^{*}$ & $38(31.67 \%)$ & \\
GG & $65(54.25 \%)$ & $64(53.33 \%)$ & 18.18 \\
GA & & & \\
Allele & $75(24.51 \%)$ & $100(41.67 \%)$ & $<0.001$ \\
A & $231(75.49 \%)^{*}$ & $140(58.33 \%)$ & \\
G & & & \\
\hline
\end{tabular}

${ }^{*} \mathrm{P}<0.05$.

Table 7. Statistical analysis of the frequencies of the HSP70-hom +2437 genotype and alleles in the GD and control groups.

\begin{tabular}{lccc}
\hline & GD group & Control group & $X^{2}$ \\
\hline Genotype & $7(4.58 \%)$ & & 0.134 \\
AA & $90(58.82 \%)$ & $68(5 \%)$ & \\
GG & $56(36.60 \%)$ & $46(38.33 \%)$ & \\
GA & & & 0.935 \\
Allele & $70(22.88 \%)$ & $58(24.17 \%)$ & \\
A & $236(77.12 \%)$ & $182(75.83 \%)$ & \\
G & & & \\
\hline
\end{tabular}

\section{DISCUSSION}

HSP70 exerts a protective effect on the heart (Fu and Tupling, 2009) and brain tissue (Zhao et al., 2006), in addition to playing an important role in immunity. In this regard, HSP70 
protects cells from natural killer cells and imparts anti-infective and anti-tumor immunity through its involvement in antigen processing and presentation (Gehrmann et al., 2005). Therefore, changes in HSP70 functionmay contribute to the development and progression of autoimmune diseases. HSP70 gene polymorphisms have been associated with the development of GD in other countries. However, to the best of our knowledge, such studies among the Chinese population have not been reported. Therefore, this study attempted to identify any such possible correlation in Chinese patients.

HSP70 gene polymorphisms within the HLA III region have been subject to close scrutiny, given its close association with a variety of autoimmune diseases, including systemic lupus erythematosus (Fürnrohr et al., 2010), autoimmune arthritis (Wieten et al., 2010), and Crohn's disease (Chen et al., 2013). As a multigene family, inheritance and variations in HSPs have occurred throughout the evolutionary process.

HSP polymorphisms are restricted to the HSP70 family. The HSP70-1 gene is polymorphic at the 110th $(\mathrm{A} / \mathrm{C})$, 120th $(\mathrm{T} / \mathrm{C})$, 190th $(\mathrm{G} / \mathrm{C})$, and 438th $(\mathrm{C} / \mathrm{T})$ loci, whereas the HSP70-2 gene is polymorphic at the 145th (A/G), 1267th (A/G), 2074th (G/C), and 2257th loci. Among these, the HSP70-1+190 and HSP70-2+1267 loci have been correlated with multiple diseases, such as diabetic nephropathy (Buraczynska et al., 2009), gastric cancer, and gastric ulcers (Shibata et al., 2009), in addition to GD.

The frequencies of the HSP70-2 +1267 GG genotype and G allele were noticeably increased in the GD group compared to the control group (42.48 vs $31.67 \%$, P $<0.01$, Table 6 ). Ratanachaiyavong et al. (1991) reported that the 8.5-kb Pst HSP70 allele is strongly associated with GD in the British Caucasian population. Hunt et al. (2001) reported an association between the gene polymorphisms at loci HSP70-1 +190 and HSP70-2 +1267 and GD in Caucasian subjects in the United Kingdom. Our results were basically consistent with the results previously reported in literature, thereby supporting the conjecture that the HSP70-2 +1267 GG genotype is a risk factor for GD. However, the frequencies of the HSP70-1 +190 G/C and HSP70-hom +2437 genotypes did not differ significantly between the GD and control groups in our study (Tables 5 and 7 ). This result contradicted those reported by Hunt et al. (2001); this discrepancy may be attributed to ethnical or regional differences between the subjects.

HSP70 is highly expressed in thyroid tissue (Trieb et al., 1993). The HSP70-2 +1267 locus is located in the coding region of the gene. Pociot et al. (1993) suggested that HSP70-2 +1267 GG homozygotes exhibit reduced HSP70 mRNA levels. The consequent reduction in protein levels may lead to impairment in the responses to cell stress and accumulation of denatured proteins, which may eventually contribute to GD progression. Further functional analyses should be performed to elucidate the specific role of the HSP70 gene in GD pathogenesis.

This study has some limitations. Firstly, the study was conducted in a small sample population. Therefore, the novel observations of this study must be validated in a larger population subset. In addition, functional studies are required to elucidate the involvement of HSP70 genes in GD complications.

In conclusion, the HSP70-2 +1267 GG genotype and G alleles may increase the risk of GD in the Chinese population. The results of this study may be useful in identifying patients with increased risk of GD, and provide useful data for targeted gene treatment of GD in the future. Based on this study, additional studies are warranted to enable further understanding of the immunoregulatory functions of HSP70 gene products under both physiological and pathological conditions, and to elucidate the significance of the resulting associations. 


\section{Conflicts of interest}

The authors declare no conflict of interest.

\section{ACKNOWLEDGMENTS}

Research supported by the National Natural Science Foundation of China (\#81460154).

\section{REFERENCES}

Buraczynska M, Swatowski A, Buraczynska K, Dragan M, et al. (2009). Heat-shock protein gene polymorphisms and the risk of nephropathy in patients with type 2 diabetes. Clin. Sci. 116: 81-86.

Chen J, Ren J, Gu G, Wang G, et al. (2013). Crohn's disease and polymorphism of heat shock protein gene HSP70-2 in the Chinese population. J. Gastroenterol. Hepatol. 28: 814-818.

Fu M and Tupling AR (2009). Protective effects of HSP70 on the structure and function of SERCA2a expressed in HEK-293 cells during heat stress. Am. J. Physiol. 296: H1175-H1183.

Fürnrohr BG, Wach S, Kelly JA, Haslbeck M, et al. (2010). Polymorphisms in the HSP70 gene locus are genetically associated with systemic lupus erythematosus. Ann. Rheum. Dis. 69: 1983-1989.

Gabai VL, Meriin AB, Mosser DD, Caron AW, et al. (1997). HSP70 prevents activation of stress kinases. A novel pathway of cellular thermotolerance. J. Biol. Chem. 272: 18033-18037.

Gehrmann M, Marienhagen J, Eichholtz-Wirth H, Fritz E, et al. (2005). Dual function of membrane-bound heat shock protein 70 (HSP70), Bag-4, and Hsp40: protection against radiation-induced effects and target structure for natural killer cells. Cell Death Diff. 12: 38-51.

Hammerstad SS, Tauriainen S, Hyöty H, Paulsen T, et al. (2013). Detection of enterovirus in the thyroid tissue of patients with Graves' disease. J. Med. Virol. 85: 512-518.

Hammerstad SS, Jahnsen FL, Tauriainen S, Hyöty H, et al. (2014). Immunological changes and increased expression of myxovirus resistance protein A in thyroid tissue of patients with recent onset and untreated Graves' disease. Thyroid 24: 537-544.

Hunt PJ, Marshall SE, Weetman AP, Bunce M, et al. (2001). Histocompatibility leucocyte antigens and closely linked immunomodulatory genes in autoimmune thyroid disease. Clin. Endocrinol. (Oxf.) 55: 491-499.

Jin X, Wang R, Xiao C, Cheng L, et al. (2004). Serum and lymphocyte levels of heat shock protein 70 in aging: a study in the normal Chinese population. Cell Stress Chaperones 9: 69.

Lu ZY and Zhong NS (2008). Internal Medicine. People's Medical Publishing House, Beijing.

Pociot F, Rønningen K and Nerup J (1993). Polymorphic analysis of the human MHC-linked heat shock protein 70 (HSP70-2) and HSP70-Hom genes in insulin-dependent diabetes mellitus (IDDM). Scand. J. Immunol. 38: 491-495.

Ratanachaiyavong S, Demaine AG, Campbell RD and McGregor AM (1991). Heat shock protein 70 (HSP70) and complement C4 genotypes in patients with hyperthyroid Graves' disease. Clin. Exp. Immunol. 84: 48-52.

Shibata T, Arisawa T, Tahara T, Yoshioka D, et al. (2009). Protective role of genetic polymorphism of heat shock protein $70-2$ for gastric cancer risk. Dig. Dis. Sci. 54: 70-74.

Streetman DD and Khanderia U (2003). Diagnosis and treatment of Graves' disease. Ann. Pharmacother. 37: 1100-1109.

Trieb K, Sztankay A, Hermann M, Gratzl R, et al. (1993). Do heat shock proteins play a role in Graves' disease? Heat shock protein-specific T-cells from Graves' disease thyroids do not recognize thyroid epithelial cells. J. Clin. Endocrinol. Metab. 77: 528-535.

Vita R, Lapa D, Trimarchi F and Benvenga S (2014). Stress triggers the onset and the recurrences of hyperthyroidism in patients with Graves' disease. Endocrine 48: 1-10.

Westman P, Partanen J, Leirisalo-Repo M and Koskimies S (1994). HSP70-Hom Ncol polymorphism and HLA-associations in the Finnish population and in patients with ankylosing spondylitis or reactive arthritis. Eur. J. Immunogenet. 21: 81-90.

Wieten L, van der Zee R, Spiering R, Wagenaar-Hilbers J, et al. (2010). A novel heat-shock protein coinducer boosts stress protein HSP70 to activate T cell regulation of inflammation in autoimmune arthritis. Arthritis Rheum. 62: 1026-1035.

Zhao J, Sun S and Chen X (2006). Protective effects of focal ischemic preconditioning and HSP70 expression on middle cerebral artery occlusion in rats. J. Huazhong Univ. Sci. Technolog. Med. Sci. 26: 436-439.

Zheng L, Wang X, Xu L, Wang M, et al. (2015). Foxp3 gene polymorphisms and haplotypes associate with susceptibility of Graves' disease in Chinese Han population. Int. Immunopharmacol. 25: 425-431. 